\title{
Hypoxia promotes glycogen synthesis and accumulation in human ovarian clear cell carcinoma
}

\author{
YASUSHI IIDA $^{1}$, KATSUHIKO AOKI $^{2}$, TADASHI ASAKURA $^{2}$, KAZU UEDA $^{1}$, \\ NOZOMU YANAIHARA ${ }^{1}$, SATOSHI TAKAKURA ${ }^{1}$, KYOSUKE YAMADA $^{1}$, \\ AIKOU OKAMOTO $^{1}$, TADAO TANAKA ${ }^{1}$ and KIYOSHI OHKAWA ${ }^{2}$
}

Departments of ${ }^{1}$ Obstetrics and Gynecology and ${ }^{2}$ Biochemistry, The Jikei University School of Medicine, Tokyo, Japan

Received December 19, 2011; Accepted February 15, 2012

DOI: 10.3892/ijo.2012.1406

\begin{abstract}
Ovarian clear cell carcinoma (OCCC) has several significant characteristics based on molecular features that are distinct from those of ovarian high-grade serous carcinoma. Cellular glycogen accumulation is the most conspicuous feature of OCCC and in the present study its metabolic mechanism was investigated. The amount of glycogen in cells cultured under hypoxia increased significantly and approximately doubled after $48 \mathrm{~h}(\mathrm{P}<0.01)$ compared to that under normoxic conditions. Periodic acid-Schiff positive staining also demonstrated intracellular glycogen storage. Western blot analysis revealed that HIFl $\alpha$, which was overexpressed and stabilized under hypoxic conditions, led to an increase in the levels of cellular glycogen synthase 1, muscle type (GYS1), and conversely to a decrease in inactive phosphorylated GYS1 at serine (Ser) 641. Additional increases were observed in both protein phosphatase 1, which dephosphorylates and thereby induces GYS1 enzyme activity, and glycogen synthase kinase 3 beta (GSK3 $\beta$ ) phosphorylated at Ser9, which is inactive on phosphorylation of GYS1 and subsequently induces its enzyme activity. By contrast, the level of PYGM-b decreased. These results indicated that the glycogen accumulation under a hypoxic environment resulted in the promotion of glycogen synthesis, but did not lead to inhibition of glycogen degradation and/or consumption. Under hypoxic conditions, HAC2 cells showed activation of the PI3K/AKT pathway caused by a mutation in exon 20 of PIK3CA, encoding the catalytic subunit $\mathrm{p} 110 \alpha$ of PI3K. The resulting activation of AKT (phosphoSer473) also plays a role as a central enhancer in glycogen synthesis through suppression of GSK $3 \beta$ via phosphorylation at Ser9. Hypoxia decreased the cytocidal activity of cisplatin and doxorubicin to various degrees. In conclusion, the hypoxic conditions together with HIF1 expression and stabilization increased the intracellular glycogen contents and resistance to the anticancer drugs.
\end{abstract}

Correspondence to: Dr Yasushi Iida, Department of Obstetrics and Gynecology, The Jikei University School of Medicine, 3-25-8 NishiShinbashi, Minato-ku, Tokyo 105-8461, Japan

E-mail: surf-side@hotmail.co.jp

Key words: ovarian clear cell carcinoma, HIF1, glycogen storage, drug resistance

\section{Introduction}

Ovarian cancer still remains the most lethal form of gynecologic malignancy. In Japan, ovarian cancer is the eighth leading cause of death from cancer in woman, but a steady upward trend has become evident in recent years. Ovarian clear cell carcinoma (OCCC) has a higher incidence in Japan at $24.7 \%$ of all epithelial ovarian cancers (1), than in North America and Europe (1-12\%) (2-5). OCCC has clinical characteristics and pathologic significance based on molecular features that are distinct from high-grade serous carcinoma of the ovary (6). Unfortunately, some studies reported that OCCC may be relatively resistant to standard platinum-based chemotherapy (7-11). It is necessary to improve our understanding of pathobiologic characteristics of OCCC in order to develop new therapeutic strategies and administer current treatment effectively.

The intracellular storage of glycogen is one of the most conspicuous pathodiagnostic features of OCCC (6). Clarification of the mechanism of these metabolic characteristics may yield a new strategy to overcome the disease. Several studies have considered the mechanism of facilitated glycogen accumulation of OCCC $(12,13)$, but a conclusion has not yet been reached. Some studies have found that the glycogen accumulation in several kinds of tumor cells was accelerated under hypoxic conditions (14-18). Under such a hypoxic environment, hypoxia-inducible factor 1 (HIF1) is expressed and functions as the main factor regulating the metabolism of the cell (19). HIF1 is a heterodimeric transcription factor that consists of an $\mathrm{O}_{2}$-regulated HIF1 $\alpha$ and a constitutively expressed HIF1 $\beta$ subunit (20). HIF $1 \alpha$ is unstable in well-oxygenated tissues owing to ubiquitin-mediated proteasomal degradation, but rapidly becomes stable under hypoxic conditions (19). Two kinds of hydroxylation enzyme (prolylhydroxylase and asparaginylhydroxylase) act in the functional maintenance of HIF1 $\alpha$. To initiate the degradation process in well-oxygenated cells, HIFl $\alpha$ is hydroxylated on a proline residue at 402 (Pro402) and/or Pro564 in the oxygen-dependent degradation domain (ODDD) by HIF-prolyl-4-hydroxylase (PHD) enzyme family, mainly PHD2, which comprises HIF1 downstream expressing genes (21). Prolyl-hydroxylated HIF1 $\alpha$ is bound and ubiquitinylated by the von Hippel-Lindau tumor suppressor protein (pVHL), which recruits an E3-ubiquitin ligase that targets HIF1 $\alpha$ for proteasomal degradation (22). HIF1 regulates the transcription of over hundreds of genes that 
encode proteins involved in every aspect of cancer biology, including cell immortalization and stem maintenance, genetic instability, glucose and energy metabolism, vascularization, autocrine growth factor signaling, invasion and metastasis, immune evasion, and resistance to chemotherapy and radiation therapy (23). It is well known that HIF1 promotes catabolism for energy production in many kinds of tumor cells mainly under an anaerobic microenvironment, which is the so-called Warburg effect (19). The present study demonstrated that hypoxia induced and enhanced cellular accumulation of glycogen in a human PIK3CA-mutation-positive OCCC cell line, HAC2, via stabilization rather than overexpression of HIF1 protein and also determined the manifestation of chemoresistance under such conditions. Prevention and treatment strategies based on the metabolic properties of the OCCC were determined.

\section{Materials and methods}

Cell culture, hypoxic exposure and DFO treatment. The human OCCC cell line, HAC2, was kindly provided by Dr M. Nishida (National Hospital Organization Kasumigaura Medical Center). HAC2 was cultured in RPMI-1640 supplemented with $10 \%$ heatinactivated fetal bovine serum (Invitrogen, USA). Normoxic cells were maintained conventionally at $37^{\circ} \mathrm{C}$ in $5 \% \mathrm{CO}_{2}$ incubator ( $21 \% \mathrm{O}_{2}$ concentration). Hypoxic cells were exposed to hypoxic conditions of $1 \% \mathrm{O}_{2}, 5 \% \mathrm{CO}_{2}$ and $94 \% \mathrm{~N}_{2}$ at $37^{\circ} \mathrm{C}$ for up to $48 \mathrm{~h}$ using an MIC-101 modular incubator chamber (BillupsRothenberg, Inc., USA). Hypoxia was consistently monitored by an OX-02G gas monitor (Riken Keiki, Japan). To ensure the precise expression of HIF1 $\alpha$, deferoxamine (DFO, Wako, Japan), which is a potent hypoxia-inducing iron-chelating material, was added to the culture medium. For DFO treatment, the cells were incubated for relatively short time of 6 hours (h) in medium with $50 \mu \mathrm{M}$ DFO because of the severe cytotoxic effect. Human ovarian cancer cell line, 2008 was provided by Dr S.B. Howell (UCSD, San Diego, USA). A2780 and OV1063 were obtained from European Collection of Cell Cultures (UK) and American Type Culture Collection (Rockville, USA), respectively. Human OCCC cell lines (JHOC5, JHOC7 and JHOC9) were obtained from Riken Bioresource Center (Tsukuba, Japan).

Quantitative assays of glycogen. After washing the cultured cells with cold $20 \mathrm{mM}$ Tris- $\mathrm{HCl}$, pH 7.4, with $0.15 \mathrm{M} \mathrm{NaCl}$, (Tris-buffered saline, TBS), glycogen was extracted with $30 \%$ $\mathrm{KOH}$ from the cells and the extracts were boiled at $100^{\circ} \mathrm{C}$ for $15 \mathrm{~min}$, followed by precipitation with $100 \%$ ethyl alcohol. After centrifugation $(16,000 \mathrm{x} \mathrm{g}$ for $10 \mathrm{~min})$ at $4^{\circ} \mathrm{C}$, the pellet was re-suspended in $70 \%$ ethyl alcohol and re-centrifuged. The resultant glycogen precipitate was dissolved in $0.1 \mathrm{M}$ sodium acetate. Glycogen was measured spectrophotometrically (infinite M200PRO, Tecan, Switzerland) using Glycogen Assay Kit (Bio Vision, USA). The results were expressed in $\mu \mathrm{g}$ of glycogen per $\mathrm{mg}$ of protein.

Sodium dodecylsulphate-polyacrylamide gel electrophoresis (SDS-PAGE) and Western blot analysis. After washing once with ice-cold TBS, cells were harvested, lyzed with SDS-PAGE sample buffer (50 mM Tris-HCl, pH 6.8, 2\% SDS, $10 \%$ glycerol, $0.05 \%$ bromophenol blue) and immediately boiled at $100^{\circ} \mathrm{C}$ for 5 min. Lots of each sample $(50 \mu \mathrm{g})$ were subjected to SDS-PAGE on $10 \%$ polyacrylamide gel and electrophoresed. The fractionated proteins were transferred to PVDF filters (Bio-Rad, USA), then blocked with blocking buffer (TBS, $0.05 \%$ Tween-20, $0.1 \%$ casein, $0.1 \%$ gelatin, and $0.02 \% \mathrm{NaN}_{3}$ ), and the filters were incubated for $17 \mathrm{~h}$ at $4^{\circ} \mathrm{C}$ with the respective primary antibodies. Primary antibodies used were murine monoclonal antibodies against human HIF1 $\alpha$, Vimentin (VIM), E-cadherine (CDH1), VHL, heat shock protein (HSP)70, HSP90, plasminogen activator inihibitor 1 (PAI1), extracellular signal regulated kinase 1/2 (ERK1/2), phosphatase and tensin homolog (PTEN), P21 ${ }^{\mathrm{WAF} 1}$ (WAF1) (BD Biosciences, Japan), ERK1/2 diphosphorylated at Thr183 and Tyr185 (p-ERK1/2), $\beta$-actin, $\alpha$-tubulin (Sigma-Aldrich Japan, Japan), CD73 (Abcam, Japan), rabbit monoclonal antibodies against glycogen synthase 1, muscle type (GYS1), glycogen synthase kinase $3 \beta$ phosphorylated at Ser9 [p-GSK3 $\beta$ (ser9)], Notch1, cMET, protein phosphatase 1 (PPP1A), mammalian target of rapamycin phosphorylated at Ser248 (p-mTOR) (Epitomics Inc., USA), rabbit polyclonal antibodies against protein phosphatase 1, regulatory subunit 3C (PPP1R3C), pyruvate dehydrogenase kinase 1 (PDK1), prolyl-4-hydroxylase 2 (PHD2), carbonic anhydrase 9 (CA9), FK506-binding protein 38 (FKBP38), glucose transporter isoform 1 (GLUT1), glycogen phosphorylase, muscle type, dephosphorylated form (PYGM-b), matrix metalloproteinase 14 (MMP14), m-TOR (Abcam), monocarboxylate transporter 4 (MCT4) (Sigma-Aldrich Japan), and hexokinase 2 (HK2) (Santa Cruz Biotechnol. Inc., USA), AKT, AKT phosphorylated at Ser473 (p-AKT), GYS1 phosphorylated at Ser641 (p-GYS1) (Cell Signaling Technology Inc., USA). After $17-\mathrm{h}$ incubation at $4^{\circ} \mathrm{C}$, the filters were further incubated with horseradish peroxidase-conjugated secondary antibodies against mouse or rabbit IgG (1:5000, Cell Signaling Technology) for $2 \mathrm{~h}$ at $37^{\circ} \mathrm{C}$. The signal was detected by the ImmunoStar LD chemiluminescence system (Wako), and the images were captured by Light Capture II (Atto, Japan). Digital images of bands were analyzed by the NIH Image J, 1.45 software.

Morphologic examination. Cells cultured using the Lab-Tek chamber slide (Thermo Fisher Scientific, USA) under hypoxic or normoxic conditions were fixed with $10 \%$ formalin in TBS, washed with TBS and dehydrated by graded concentrations of ethyl alcohol. For tumor tissues transplanted in nude mice, the resected tissue samples were washed once with cold TBS and fixed with $10 \%$ formalin in TBS, then routinely processed and embedded in paraffin. Both fixed cultured cells and deparaffinized tissue sections were stained by hematoxylin and eosin and periodic acid-Schiff (PAS) with or without diastase digestion.

RNA extraction and RT-PCR. After culturing the cells, total RNA was extracted using the RNeasy kit (Qiagen, Japan), and the concentration was determined by a spectrophotometer (Hitachi, Japan). Reverse transcription was carried out using the PrimeScript II 1st Strand cDNA Synthesis Kit (Takara, Japan). cDNAs were then amplified using GoTaq Green Master Mix (Promega, USA) with a pair of gene-specific primers. Primer sequences for the analyzed genes are shown in Table I.

Xenotransplantation of HAC2 cells into nude mice and preparation of tissue extracts. HAC2 cells $\left(5 \times 10^{6}\right)$ were transplanted into the subcutaneous tissue of the lateral abdominal wall of 
Table I. PCR primer.

\begin{tabular}{lll}
\hline Gene & \multicolumn{1}{c}{ Forward primer } & \multicolumn{1}{c}{ Reverse primer } \\
\hline$H N F 1 B$ & 5'-CCCGACACCAAGCCGGTCTT-3' & 5'-ACTGTCTGGTTGAATTGTCGGAGG-3' \\
$H I F 1 A$ & 5'-GAAAGCGCAAGTCCTCAAAG-3' & 5'-TGGGTAGGAGATGGAGATGC-3' \\
ABCB1 & 5'-GACTGAGCCTGGAGGTGAAG-3' & 5'-CCACCAGAGAGCTGAGTTCC-3' \\
ABCC1 & 5'-TGGAACAAGCTGAACGTGAG-3' & 5'-CACAGTGAGCAGGAACCAGA-3' \\
$T O P 2 A$ & 5'-TGAGATTTAAGCCCCCTCCT-3' & 5'-TGCGATAAACTCCCTCATCC-3' \\
$T O P 2 B$ & 5'-GTTTACTTGCTTCAAACGGA-3' & 5'-CAGGACCACCCAGTACCGAT-3' \\
\hline
\end{tabular}

male nude mice (BALB/c nu/nu, 5-weeks old, Clea, Japan) under specific pathogen-free conditions. Eleven weeks after the transplantation, tumor tissues were removed and homogenized. The harvested tumor tissues were rinsed immediately with cold TBS. For RNA preparation, tumor tissue fragments were homogenized in Buffer RLT Plus (Qiagen) with 1\% 2-mercaptoethanol and the total RNA was isolated by the same procedure as described in the above section. For protein preparation, some tumor fragments were homogenized in $50 \mathrm{mM}$ Tris- $\mathrm{HCl}, \mathrm{pH} 7.5,0.1 \%$ SDS, $1 \mathrm{mM}$ EDTA, $1 \%$ TritonX-100, $1 \%$ deoxycholate, $1 \mathrm{mM} \mathrm{Na}_{3} \mathrm{VO}_{4}$, $1 \mathrm{mM} \mathrm{NaF}$, protease inhibitor cocktail and phosphatase inhibitor cocktail 1, 2 (Sigma-Aldrich). After incubation for $20 \mathrm{~min}$ on ice followed by centrifugation $(16,000 \times \mathrm{g}$ for $20 \mathrm{~min})$ at $4^{\circ} \mathrm{C}$, SDS-PAGE sample buffer (5-fold concentration) was added to the supernatant and boiled. All animal studies were performed in conformity with the Guidelines on Animal Experimentation of the Jikei University containing rules of ethics on animal experimentation.

Analyses of gene mutations. Exons 9 and 20 of the PIK3CA gene encoding phosphatidyl inositol-4, 5-biophosphate 3-kinase catalytic subunit $\alpha$ isoform (PI3K p110 subunit $\alpha$, EC2.7.1.153) and $V H L$ in $\mathrm{HAC} 2$ cells were amplified using PCR. Purification of cDNA and the PCR method were as described in the above section. The primers for PIK3CA were the same as described previously (24), briefly, exon 9: forward, 5'-CCAGAGGGGA AAATATGACAA-3'; reverse, 5'-ACCTGTGACTCCATAG AAA-3'. Exon 20: forward, 5'-TTGATGACATTGCATACAT TCG-3'; reverse, 5'-AATTGTGTGGAAGATCCAATCC-3'. Primers for VHL used were as follows: forward, 5'-GAAGACT ACGGAGGTCGACT-3'; reverse, 5'-TGACGATGTCCAGTCT CCTG-3' and forward, 5'-CCCAGGTCATCTTCTGCAAT-3'; reverse, 5'-GGAACCAGTCCTGTATCTAG-3'.

Each RT-PCR product was electrophoresed on $1.5 \%$ agarose gel (Wako) in Tris-acetate buffer, $1.26 \mu \mathrm{M}$ ethidium bromide. Amplified PCR products were purified with Wizard SV Gel and PCR Clean-Up System (Promega). They were subsequently subjected to direct sequencing PCR with BigDye terminator v3.1/1.1 cycle sequencing reagents (Applied Biosystems, USA) and were analyzed with the Applied Biosystems 3730xl DNA Analyser (Applied Biosystems) with basic BLAST in NCBI. When a mutation(s) was detected by sequencing analysis, genetic analysis was repeated at least twice from the step of genomic DNA amplification.
Cytotoxicity assay. After washing once with calcium-free Dulbecco's phosphate buffered saline [PBS(-)], cells were detached with $0.125 \%$ trypsin and $0.02 \%$ EDTA in PBS(-). The cells $\left(2 \times 10^{4}\right.$ cells/well) were seeded into a 48 -well culture plate (Greiner Bio One, Germany) containing $500 \mu \mathrm{l}$ of medium with various concentrations of cisplatin (CDDP, Sigma-Aldrich Japan) or doxorubicin (DXR, Sigma-Aldrich Japan) and incubated continuously for $96 \mathrm{~h}$ under conditions of normoxia or hypoxia. To prepare cells cultured under hypoxic conditions, the cells were precultured for $48 \mathrm{~h}$ under hypoxic conditions as stated above and then detached in a hypoxic chamber before assay. After 96-h incubation with test materials under respective hypo- and normo-oxygen conditions, $40 \mu \mathrm{l}$ of Cell Titer 96 Aqueous MTS solution (Promega) was added to each well and the plates were incubated for additional 3-h period under normoxic conditions. Absorbance at $490 \mathrm{~nm}$ for each well was measured using a microtiter plate reader (infinite M200PRO). The cell viability was expressed as the fraction of surviving cells relative to untreated controls and the 50\% growth inhibition concentration $\left(\mathrm{IC}_{50}\right)$ was calculated.

Protein concentration. The protein concentration was measured by the DC protein assay kit (Bio-Rad). Bovine serum albumin was used as the standard.

Statistical determination. When indicated, data were given as means \pm SD with $n$ indicating the number of experiments. One-way analysis of variance and t-tests were applied for the statistical analysis, as appropriate, using the StatMate software (ATMS, Japan). Values were considered significant at $\mathrm{P}<0.05$.

\section{Results and Discussion}

Expression of proteins under hypoxia. Under hypoxic environment, HAC2 cells showed slight but non-significant growth retardation as compared with that under normoxic condition. HAC2 cells expressed the hepatocyte nuclear factor-1 $\beta$ (Fig. 1), a representative gene expressed in OCCC, as reported previously (25). Under the culture condition of low oxygen, mRNA of HIF1 $\alpha$ in HAC2 cells was somewhat overexpressed at certain points of time (Fig. 1), and protein was stabilized at increased levels as compared to that of normoxic cells. Expressed and stabilized HIFl $\alpha$ simultaneously promoted transcription of many genes crucial for cellular response to hypoxia including cell survival, 
A

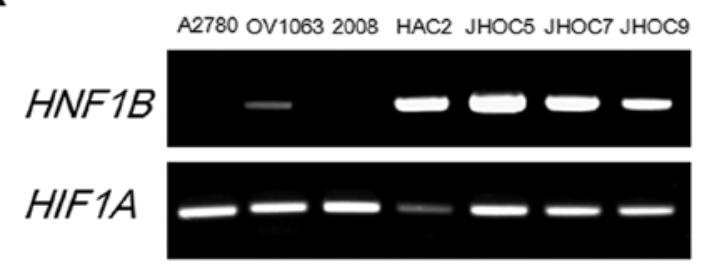

B

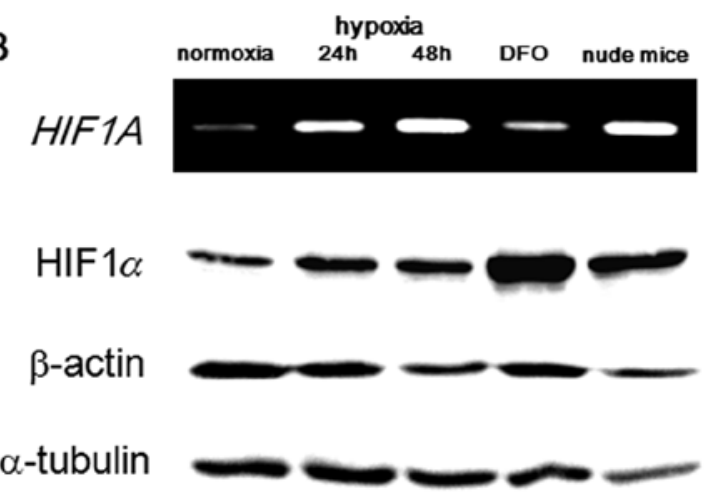

Figure 1. HAC2 and other OCCCs expressed various levels of HNF1 $\beta$ and HIF1. (A) Each cell line cultured under normoxia was lyzed and mRNAs were extracted for RT-PCR followed by agarose gel electrophoresis. (B) HAC2 cells were cultured under normoxia for $48 \mathrm{~h}$ or hypoxia for 24 and $48 \mathrm{~h}$, or normoxia for $6 \mathrm{~h}$ with DFO. Cells cultured under each condition were lyzed. mRNA for RT-PCR and protein for SDS-PAGE followed by Western blotting were obtained. HAC2, JHOC5, JHOC7 and JHOC9 were OCCC in nature. $\beta$-actin and $\alpha$-tubulin were loading controls of protein.

A
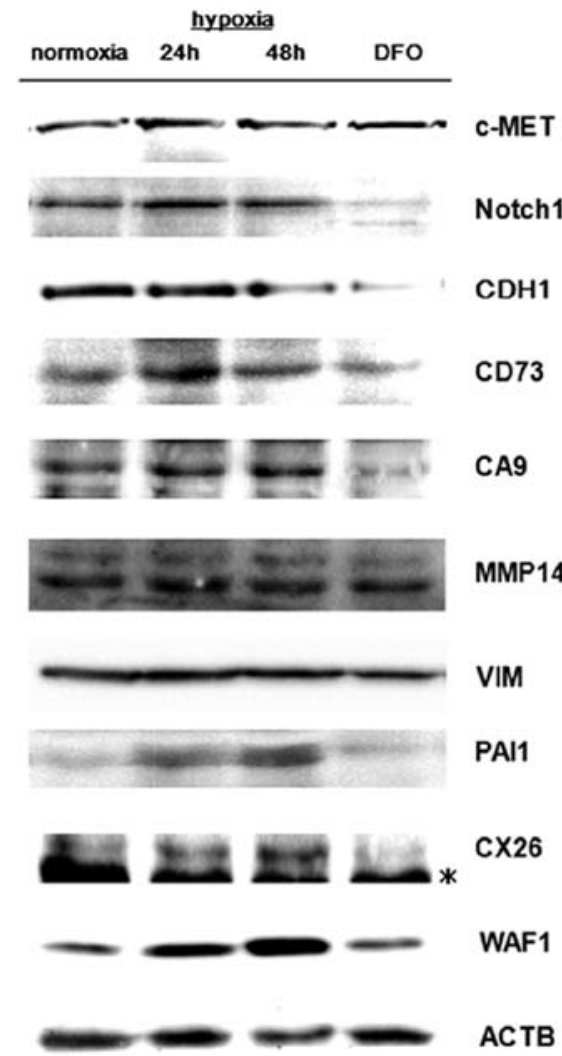

DH1

D73 angiogenesis, cell motility and invasion as shown (Fig. 2A). HIF1 also regulates the expression of the genes involved in glucose metabolism. HIF1 downstream targets, such as GLUT1, HK2, PDK1, MCT4, were significantly increased in terms of levels of proteins under hypoxia compared to normoxia (Fig. 2B).

The stability and function of HIF1 are mainly regulated by PHD-driven hydroxylation of ODDD, followed by pVHL-caused ubiquitinylation and proteasomal degradation (21). In the present study, the $V H L$ gene from HAC2 cells did not manifest any genetic mutations in the DNA sequence and was compatible with that from normal cells as reported previously (26). Furthermore, pVHL expression without loss of function in HAC2 cells did not show any difference between cells cultured under normoxic and hypoxic conditions (Fig. 2C). It is well known that both somatic and germline abnormalities of the $V H L$ gene play a pivotal role in the carcinogenesis of renal clear cell carcinomas (27-32) but have not been reported in OCCC (0/74 ovarian samples in COSMIC) (6). Our present study also demonstrated that a $V H L$ mutation did not appear in OCCC, different from renal clear cell carcinoma. In contrast, in the initial $24 \mathrm{~h}$ after hypoxic culture, the occurrence was noted of continuous 48 -h overexpression and stabilization of PHD2, which is a HIF1 downstream gene and the main HIF1 $\alpha$ regulator via hydroxylation of ODDD $(33,34)$, and also of transient downregulation of FKBP38, a key regulator in the stabilization and function of PHD2 by binding, followed by proteasomal degradation (35-37) (Fig. 2C). Since the function of PHD2 is downregulated via molecular interaction between FKBP38 and PHD2 protein, HIF1 $\alpha$ protein stability is prolonged by the inhibition of PHD2, to which the

B
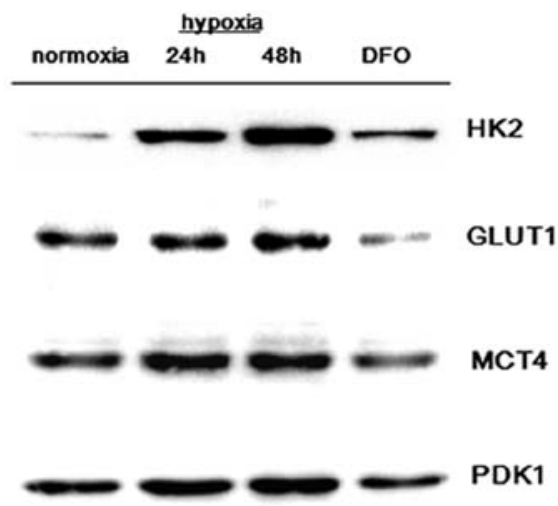

\section{C}
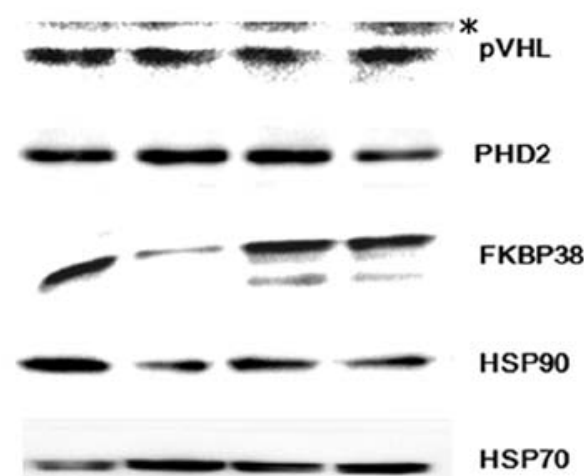

Figure 2. HIF1-downstream (A and B) and HIF1-regulating (C) gene products. Cells cultured under each condition described in Fig. 1B were lyzed and then SDS-PAGE, followed by Western blotting were performed. For details, see Materials and methods. 

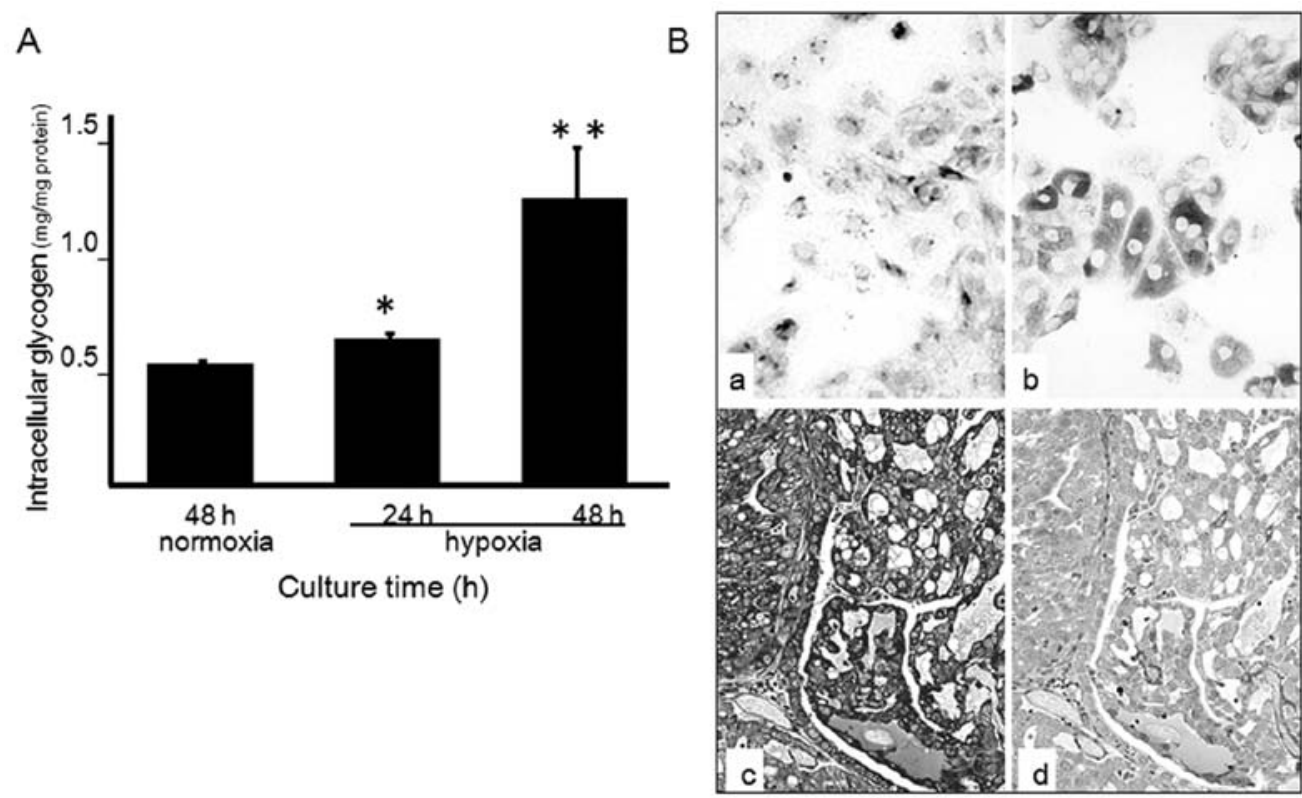

Figure 3. Hypoxia promoted glycogen accumulation in vitro and in vivo. (A) After alkaline-extraction followed by ethanol precipitation from cells cultured under normoxia or hypoxia, the glycogen contents were determined spectrophotometrically. Data are the means $\pm \mathrm{SD}$ of 4 independent experiments. ${ }^{* *} \mathrm{P}<0.01$, $\mathrm{P}<0.05$, significant difference from normoxia. (B) HAC2 cells cultured under normoxia (a) or hypoxia (b) on Lab-Tek chamber slides were fixed in situ by buffered formalin and stained with PAS. HAC2 tumor cells xenotransplanted into nude mice were resected, fixed with buffered formalin, and embedded in paraffin. Deparaffinized sections were stained with PAS with (d)/without (c) diastase digestion.

increased FKBP38 molecules are bound. The rapid recovery by $48 \mathrm{~h}$ under hypoxic conditions and the unchanged level with DFO treatment in this study, suggested that FKBP38 is not a HIF target, as previously reported (37). These results indicated that the early and immediate compensatory bio-responses of HAC2 cells against sudden and severe hypoxic changes were almost the same as those described in previous reports $(33,36)$. A decreased level of HSP90 and slight but detectable increased level of HSP70 were additionally found (Fig. 2C). It has been reported that HSP70/HSP90 axis is another mechanism used to stabilize HIF1 and the downregulation of HSP70 and upregulation of HSP90 induced destabilization and degradation of the HIF1 protein by means of their chaperon mechanism $(38,39)$, independently from pVHL-ubiquitin system. These results suggest that the hypoxic environment in our experiment was sufficient.

Hypoxia-induced glycogen accumulation. HAC2 cells exposed to hypoxia or normoxia were lyzed and their glycogen contents were measured at different points of time. The intracellular amount of glycogen under hypoxic conditions was increased significantly after $24 \mathrm{~h}(641.4 \pm 33.4 \mu \mathrm{g} / \mathrm{mg}$ protein, $\mathrm{P}<0.05, \mathrm{n}=4)$, and had approximately doubled after $48 \mathrm{~h}(1252.9 \pm 239.3 \mu \mathrm{g} /$ mg protein, $\mathrm{P}<0.01, \mathrm{n}=4$ ) as compared to that under normoxic condition $(533.2 \pm 16.15 \mu \mathrm{g} / \mathrm{mg}$ protein, $\mathrm{n}=4)$ (Fig. 3A). As shown from the cytologic examination (Fig. 3B), detectable PAS-positive, diastase-soluble granules in $\mathrm{HAC} 2$ cells indicated a marked increase in the cellular glycogen concentration under hypoxia. Histopathologic observations revealed that $\mathrm{HAC} 2$ cells transplanted into nude mice formed an adenocarcinoma-like glandular structure lining several large hobnail type tumor cells and had an irregular shape with bizarre nuclei. These cells also showed intracellular PAS-reactive, diastase-soluble glycogen accumulation in a large number of the tumor cells (Fig. 3B) with significantly elevated levels of HIFl $\alpha$ protein, as mentioned above in the biochemical analysis section (Fig. 1). These histologic findings were compatible with the histopathologic feature of OCCC and confirmed that the HAC2 cell line was established from OCCC tumor tissue.

Expression of several proteins related to glycogen metabolism under hypoxia. To confirm whether hypoxia modulated enzymes were involved in glycogen synthesis and/or degradation in HAC2 cells, the expressions of some enzymes related to glycogen metabolism, such as GYS1, p-GSK3 $\beta$ (Ser9), PPP1A, PPP1R3C and PYGM-b, were examined under respective normoxic and hypoxic conditions. Protein level of GYS1 was increased under hypoxic conditions. Conversely, the level of p-GYS1 in ser641 protein was diminished (Fig. 4A and B). GSK3 $\beta$ is known as a key regulator in the function of GYS1 via phosphorylation and consequent inactivation of GYS1 activity (40). In spite of the omission of a direct assay of glycogen synthase enzyme activity in this study, a previous report demonstrated that the glycogen synthase activity increased in parallel with GYS1 protein accumulation (17). Phosphorylation at Ser9 of GSK3 $\beta$ inhibits its own enzyme activity (41) and in the present study, p-GSK3 $\beta$ (Ser9) increased under hypoxia (Fig. 4C). Moreover, PPP1A and its regulatory subunit PPP1R3C were slightly but significantly elevated when $\mathrm{HAC} 2$ cells were cultured under hypoxia (Fig. 4A and B). It is well known that PPP1A catalyzes dephosphorylation of GYS1 and activates its enzyme activity, and additionally catalyzes dephosphorylation and inactivation of PYGM, contributing to further stimulation of glycogen deposition (42). In the present study, the level of PYGM-b was diminished (Fig. 4A and B) and this indicated that glycogen accumulation resulted in facilitated glycogen 
A

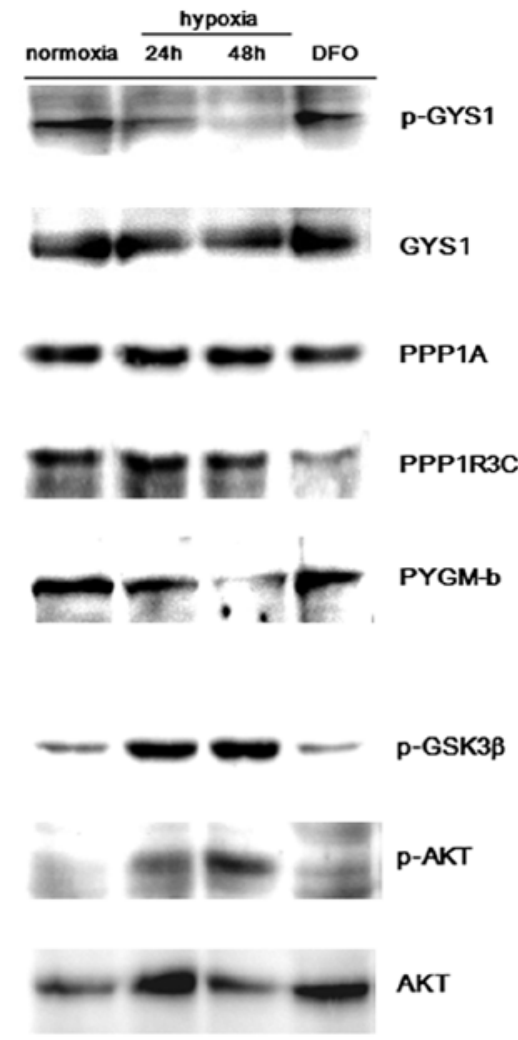

B

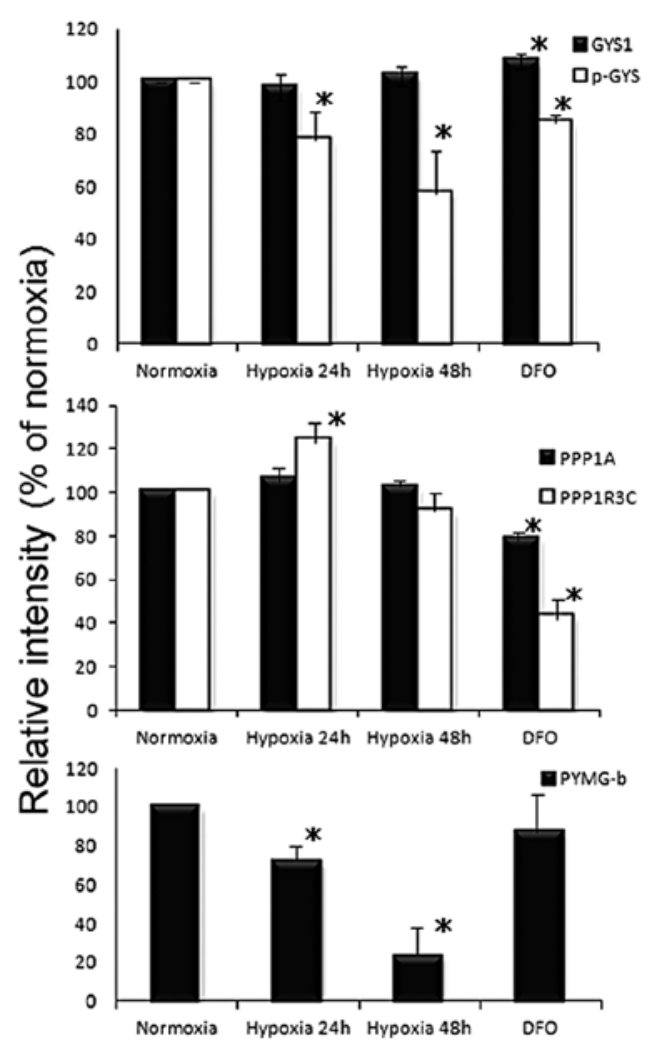

Figure 4. Glycogen storage was caused by accelerated glycogen synthesis. Western blotting procedure was the same as for Fig. 2 and representative molecular bands were analyzed densitometrically using NIH Image $\mathbf{J}$ software. The data indicated the relative \% intensity relative to normoxic expression bands. Data are the means \pm SD of 3 independent experiments. "Significant difference $(\mathrm{P}<0.05)$ compared to normoxia.

synthesis, but not in the inhibition of glycogen degradation and/or consumption. These facts partly explained why the promotion of glycogen accumulation resulted in synthesis in the HAC2 cells under hypoxia.

HAC2 cells exposed to hypoxic condition showed the activation of AKT and MAP kinase (ERK1/2). In OCCC, like numerous other cancers $(43,44)$, somatic mutations in the $P I K 3 C A$ gene have been common and highly frequent $(24,45,46)$. The PIK3CA gene, encoding the catalytic subunit p1 $10 \alpha$ of PI3K, is located on chromosome $3 \mathrm{q} 26.3$ and mutation and/or amplification of this locus has been shown to increase PI3K activity $(43,47)$. HAC2 cells used in the present study have a distinct PIK3CA mutation in exon 20 of the H1047R (A3140G) substitution (Fig. 5A), and activation of its downstream AKT and MAP kinase pathways was noticeable (Fig. 5B). Since PIK3CA gene mutation causes the continuous activation of AKT, it was not surprising in HAC2 cells that the phosphorylated AKT at Ser473 was elevated under hypoxic culture conditions as well as DFO treatment, moreover, the stabilized HIF1 $(48,49)$ was further activated by PI3K/AKT pathway, one of the main mechanisms of HIF1 activation, as reported previously (50). Additionally, it is well known that AKT regulates glycogen synthesis through phosphorylation at Ser9 followed by inactivating the GSK $3 \beta$. When the cells are exposed to hypoxic conditions, time-dependent biphasic HIF1 $\alpha$ stabilization and activation by PI3K/AKT/GSK $3 \beta$ signaling pathway has been proposed but this explanation remains controversial (50). Our present results supported part of the initial response reported in previously findings (50), although the hypoxic treatment of the cells with a different type of PIK3CA mutation was for a longer time compared with that in the previous report (50). In the present study, downregulation in p-GSK3 $\beta$ (Ser9) was promoted and the level of GSY1 in the dephosphorylated form was consequently increased and probably enhanced glycogen synthesis.

In contrast, apparent phosphorylated ERK1/2 at Thr183 and Tyr185 was noted only in cells exposed to hypoxic culture conditions and there were no detectable signals in cells treated by DFO because of the extremely short time of exposure and the effect of severe toxicity of DFO on the cells (Fig. 5B). Treatment of the target cells with DFO usually has been used to shift the cell metabolism in order to mimic hypoxic conditions (51), instead of culturing the cells under 'real' oxygen-regulated hypoxia. In the present study, however, several discrepancies were noticed, and the reasons for such differences between the two conditions were not resolved at this time. The MAP kinase signaling pathway is concerned with almost all cellular responses, including not only acceleration, but inhibition of the cell metabolism and functions under a variety of physiologic and pathologic states. Therefore, HAC2 cells exposed to hypoxia may evoke multipotential functions in their character.

HIF1-mediated epithelial-mesenchymal transition (EMT) may have occurred simultaneously in this experiment. Multifunctional GSK3 $\beta$ regulates the E-cadherin transcriptional repressor, Snail, as described in a previous report (52), via phosphorylation regulation. In the present study, E-cadherin was downregulated time-dependently by hypoxia treatment of the cells and several EMT-related gene families were activated under the experimental hypoxia (Fig. 2A and B). Our previous and other reports have indicated that the three dimensional (3D) 
A

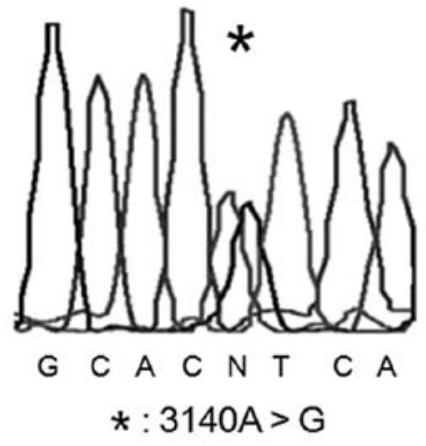

B

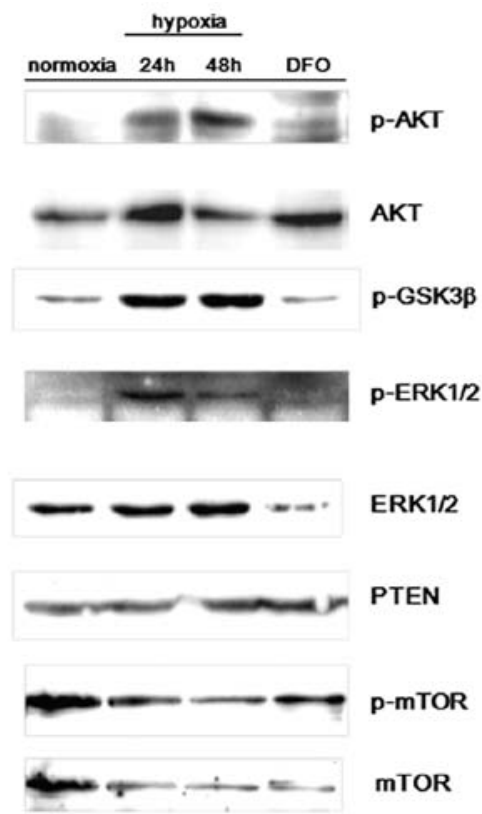

Figure 5. PIK3CA mutation activated PI3K/AKT and MAP kinase signaling pathways. Exon 20 of PIK3CA gene was amplified by RT-PCR. Purified products were analyzed with a DNA analyzer. For details, see Materials and methods. (A) Result of direct sequencing of exon 20 of PIK3CA gene. "Mutation of sequence. (B) Expression of representative molecules in PI3K/AKT and MAP kinase pathways, using methods described in Figs. 2 and 4A and C.

Table II. Cytotoxicity of cisplatin and doxorubicin on HAC2 cells.

\begin{tabular}{lll}
\hline Drug & Normoxia $(\mu \mathrm{M})$ & Hypoxia $(\mu \mathrm{M})$ \\
\hline Cisplatin & $1.51 \pm 0.07(\mathrm{n}=5)^{\mathrm{a}}$ & $2.35 \pm 0.25(\mathrm{n}=5)^{\mathrm{a}, \mathrm{b}}$ \\
Doxorubicin & $0.307 \pm 0.02(\mathrm{n}=5)^{\mathrm{a}}$ & $0.314 \pm 0.02(\mathrm{n}=5)^{\mathrm{a}, \mathrm{c}}$ \\
\hline
\end{tabular}

${ }^{\text {aD }}$ ata are presented as the means $\pm \mathrm{SD}$ of $50 \%$ growth inhibition concentration $\left(\mathrm{IC}_{50}\right)$. P-values compared to normoxia, ${ }^{\mathrm{b}} \mathrm{P}<0.001$; ${ }^{\mathrm{C}} \mathrm{NS}$, $\mathrm{P}>0.05$.

culture provided a cellular architecture similar to that of living organisms and closely mimicked the living hypoxic microenvironment without any specific modification and/or treatments, such as cell culturing under anaerobic condition or cell exposure to hypoxia-inducible reagents such as DFO (53-56). The 3D culture system may be a highly useful tool for investigating metabolic changes in cells under hypoxia without treatment, and further study is necessary to clarify whether or not some metastatic properties expressed in the OCCC without anoikis are based on EMT or MET.

Hypoxia altered sensitivity to some anticancer agents of HAC2 cells. OCCC has been demonstrated to show chemoresistance (7-11), hence its sensitivity under hypoxic conditions to CDDP, which has been used routinely in gynecologic cancer clinics, was analyzed and then compared to that under normoxic conditions. Cell viability assessed by MTT assay indicated that the $\mathrm{IC}_{50}$ of CDDP increased under hypoxic conditions $\left(\mathrm{IC}_{50} 2.35 \pm 0.25 \mu \mathrm{M}\right.$, $\mathrm{n}=5)$ as compared to normoxia $\left(\mathrm{IC}_{50} 1.51 \pm 0.07 \mu \mathrm{M}, \mathrm{n}=5\right)$ $(\mathrm{P}<0.001)$, suggesting that known and/or unknown mechanisms of resistance to CDDP under hypoxia may be upregulated and

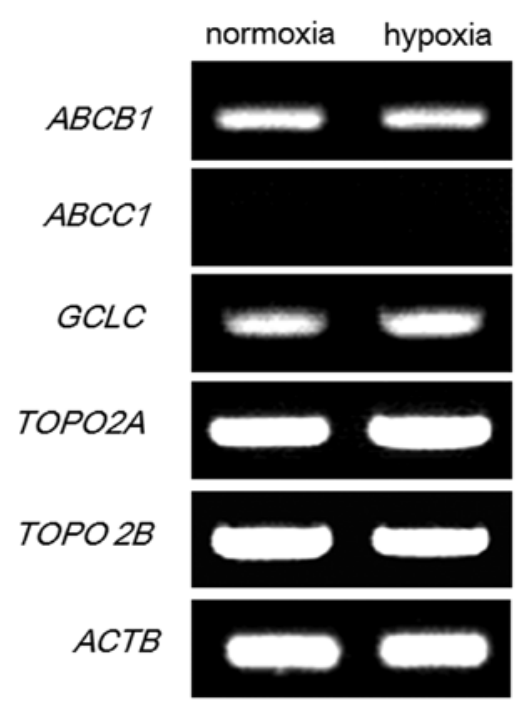

Figure 6. Expression of several drug-resistance related genes. RNA extraction from cells cultured under normoxia or hypoxia was analyzed by RT-PCR and agarose gel electrophoresis.

induced (Table II). It is of interest that the hypoxic environment did not attenuate the drug efficacy of DXR $\left(\mathrm{IC}_{50}\right.$ : hypoxia/ normoxia $=0.307 \pm 0.019, \mathrm{n}=5 / 0.314 \pm 0.018 \mu \mathrm{M}, \mathrm{n}=5)$ (Table II). The expression of some genes related to drug-resistant phenotypes was analyzed and the mRNA expression levels of $A B C B 1$, $A B C C l, \gamma$-glutamylcysteine synthetase $(G C L C)$ and DNA topoisomerase II $\alpha, \beta$ (TOP $2 A, B)$ did not show any significant difference between hypoxia and normoxia (Fig. 6), although $A B C B 1$ is reported to be one of the HIF target downstream genes (57) and its gene product, P-glycoprotein (Pgp), actively transports its typical substrates (DXR) outside the cells (58). This result indicated that $A B C B 1$ gene expression might not be sufficient to show an effect in the relatively short time of 
48-h culture. DXR, an anthracycline anticancer agent, exhibits cytotoxicity that intercalates DNA and induces TOPII-mediated strand breaks (59). A recent convincing and meaningful report (60) proposed evidence that HIF1 binds to hypoxia-responsive elements (HREs), which are cis-acting DNA sequences containing the consensus binding site to mediate HIF-inducible and -dependent transcription; moreover, anthracyclines disrupt the binding of HIF1 to HREs in vitro and probably in vivo. Another study (61) reported, however, that neither DXR nor daunorubicin inhibited the expression of HIF1-dependent genes, and that only aclacinomycine B inhibited expression. It is known that aclacinomycine B, a member of the anthracycline anticancer drug family, is not a substrate or is at most a weak substrate for Pgp (62-64). Inhibitory effect of the induction of anthracyclines on HIF-downstream genes is controversial, because the discrepancy might have been caused by the use of another experimental model of cells with unknown and various expression levels of $A B C B 1$ and/or the $A B C C$ family and related biomaterials including GSH. In the present study, DXR cytotoxicity under hypoxia did not increase, but in constrast, decreased slightly by a non-significant level as compared with that under normoxia. The result might have been off set by other GS-X pump molecules in the ABCC family in $\mathrm{HAC} 2$ cells under hypoxia having actively transported the DXR outside the cells, in spite of the inhibitory effect of DXR in HIF1 regulating transcription. Another mechanism to reduce the cytotoxicity of DXR might be that under a well-conditioned hypoxic environment, HIF1-proteins translocate into the nuclei, bind and show fully functional transcriptional activity, which may lead to competitive inhibition of the binding of DXR to DNA under such conditions. The reduced level of DXR-cytotoxicity under hypoxia was based on this competitive binding inhibition of DXR to HREs. Anticancer efficacy of DXR on ovarian cancer chemotherapy will have to be re-considered strategically again. CDDP also showed reduced cytotoxicity under hypoxia. Since CDDP exhibits cytotoxicity that intercalates the DNA strands, a slight but efficient reduction on CDDP cytotoxicity may have a considerable effect similar to that of DXR on HREs. This phenomenon requires further study to clarify the mechanism.

\section{Acknowledgements}

This study was supported in part by Grant-in-Aids for Science Research from the Ministry of Education, Culture, Sports, Science and Technology and from the Ministry of Health, Labour and Welfare, Japan, Grant-in-Aids from the New Energy and Industrial Technology Development Organization, Japan, and a Grant of The Jikei university Graduate Research Fund.

\section{References}

1. Japanese Gynecologic Cancer Committee: Annual report on Japanese gynecologic cancer committee. Acta Obstet Gynecol Jpn 61, 2009.

2. Mackay HJ, Brady MF, Oza AM, Reuss A, Pujade-Lauraine E, Swart AM, et al: Prognostic relevance uncommon ovarian histology in women with high stage III/IV epithelial ovarian cancer. Int J Gynecol Cancer 20: 945-952, 2010.

3. Piccart MJ, Bertelsen K, James K, Cassidy J, Mangioni C, Simonsen E, et al: Randamized inter group trial of cisplatin-paclitaxel versus cisplatin-cyclophosphamide in women with advanced epithelial ovarian cancer: three year results. J Natl Cancer Inst 92: 699-708, 2000
4. Vasey PA, Jayson GC, Gordon A, Gabra H, Coleman R, Atkinson R, et al: Phase III randomized trial of docetaxel-carboplatin versus paclitaxel-carboplatin as first line chemotherapy for ovarian carcinoma. J Natl Cancer Inst 96: 1682-1691, 2004.

5. Köbel M, Kalloger SE, Huntsman DG, Santos JL, Swenerton KD, Seidman JD, et al: Differences in tumor type in low-stage versus high-stage ovarian carcinomas. Int J Pathol 29: 203-211, 2010.

6. Anglesio MS, Carey MS, Kobel M, Mackay H, Huntsman DG, Vancouver Ovarian Clear Cell Symposium Speakers: Clear cell carcinoma of the ovary: a report from the first Ovarian Clear Cell Symposium, June 24th, 2010. Gynecol Oncol 121: 407-415, 2011.

7. Sugiyama T, Kamura T, Kigawa J, Terakawa N, Kikuchi Y, Kita T, et al: Clinical characteristics of clear cell carcinoma of the ovary: a distinct histologic type with poor prognosis and resistance to platinum-based chemotherapy. Cancer 88: 2584-2589, 2000.

8. Takano M, Kikuchi Y, Yaegashi N, Kuzuya K, Ueki M, Tsuda H, et al: Clear cell carcinoma of the ovary: a retrospective multicentre experience of 254 patients with complete surgical staging. Br J Cancer 94: 1369-1374, 2006.

9. Ho CM, Haung YJ, Chen TC, Haung SH, Liu FS, Chang Chien CC, et al: Pure-type clear cell carcinoma of the ovary as a distinct histological type and improved survival in patients treated with paclitaxel-platinum-based chemotherapy in pure-type advanced disease. Gynecol Oncol 94: 197-203, 2004.

10. Pectasides D, Fountzilas G, Aravantinos G, Kalofonos C, Efstathiou H, Farmakis D, et al: Advanced stage clear-cell epithelial ovarian cancer: the Hellenic Cooporative Oncology Group experience. Gynecol Oncol 102: 285-291, 2006.

11. Utsunomiya H, Akahira J, Tanno S, Moriya T, Toyoshima M, Niikura $\mathrm{H}$, et al: Paclitaxel-platinum combination chemotherapy for advanced or recurrent ovarian clear cell adenocarcinoma: a muticenter trial. Int J Gynecol Cancer 16: 52-56, 2006.

12. Kobayashi H, Yamada Y, Kanayama S, Furukawa N, Noguchi T, Haruta S, et al: The role of hepatocyte nuclear factor-1beta in the pathogenesis of clear cell adenocarcinoma of the ovary. Int J Gynecol Cancer 19: 471-479, 2009.

13. Yamaguchi K, Mandai M, Oura T, Matsumura N, Hamanishi J, Bata T, et al: Identification of an ovarian clear cell carcinoma gene signature that reflects inherent disease biology and the carcinogenic processes. Oncogene 29: 1741-1752, 2010.

14. Mamedava LK, Shneyvays V, Katz A and Shainberg A: Mechanism of glycogen supercompensation in rat skeletal muscle cultures. Mol Cell Biochem 250: 11-19, 2003.

15. Vigoda A, Mamedova LK, Shneyvays V, Katz A and Shainberg A: Glycogen metabolism in rat heart muscle cultures after hypoxia. Mol Cell Biochem 254: 311-318, 2003.

16. Savransky V, Nanayakkara A, Vivero A, Bevans S, Smith PL, Torbenson MS, et al: Chronic intermittent hypoxia predisposes to liver injury. Hepatology 45: 1007-1013, 2007.

17. Pescador N, Villar D, Cifuentes D, Garcia-Rocha M, OrtizBarahona A, Vazquez S, et al: Hypoxia promotes glycogen accumulation through hypoxia induced factor (HIF)-mediated induction of glycogen synthase 1. PLoS One 5: e9644, 2010.

18. Shen GM, Zhang FL, Liu XL and Zhang JW: Hypoxia-induced factor 1-mediated regulation of PPP1R3C promotes glycogen accumulation in human MCF-7 cells under hypoxia. FEBS Lett 584: 4366-4372, 2010.

19. Nicholas CD: Hypoxia, HIF1 and glucose metabolism in the solid tumor. Nat Rev Cancer 8: 705-713, 2008.

20. Wang GL, Jiang BH, Rue EA snd Semenza GL: Hypoxia-inducible factor 1 is a basic-helix-loop-helix-PAS heterodimer regulated by $\mathrm{O}_{2}$ tension. Proc Natl Acad Sci USA 92: 5510-5514, 1995.

21. Kaelin WG Jr and Ratciliffe PJ: Oxygen sensing by metazoans: the central role of the HIF hydroxylase pathway. Mol Cell 30: 393-402, 2008

22. Semenza GL: HIF-1: upstream and downstream of cancer metabolism. Curr Opin Dev 20: 51-56, 2010.

23. Semenza GL: Defining the role of hypoxia-inducible factor 1 in cancer biology and therapeutics. Oncogene 29: 625-634, 2010.

24. Yamamoto S, Tsuda H, Takano K, Iwaya K, Tamai S and Matsubara O: PIK3CA mutation is an early event in the development endometriosis-associated ovarian clear cell adenocarcinoma. J Pathol 225: 189-194, 2011.

25. Tsuchiya A, Sakamoto M, Yasuda J, ChumaM, Ohta T, Ohki M, et al: Expression profiling in ovarian clear cell carcinoma: identification of hepatocyto nuclear factor- 1 beta as a molecular marker and a possible molecular target for therapy of ovarian clear cell carcinoma. Am J Pathol 163: 2503-2512, 2003. 
26. Nakashima R, Enomoto T, Fujita M, Yoshino K, Wada H, Kondo K, et al: The von-Hippel-Lindau (VHL) tumor suppressor gene is not mutated in sporadic ovarian carcinoma. Oncol Rep 3: $887-890,1996$

27. Gnarra JR, Tory K, Weng Y, Schmidt L, Wei MH, Li H, et al: Mutations of the VHL tumour suppressor gene in renal carcinoma. Nat Genet 7: 85-90, 1994.

28. Nickerson ML, Jaeger E, Shi Y, Durocher JA, Mahurkar S, Zaridze D, et al: Improved identification of von Hippel-Lindau gene alterations in clear cell renal tumors. Clin Cancer Res 14 4726-4734, 2008.

29. Shuin T, Kondo K, Torigoe S, Kishida T, Kubota Y, Hosaka M, et al: Frequent somatic mutations and loss of heterozygosity of the von Hippel-Lindau tumor suppressor gene in primary human renal cell carcinomas. Cancer Res 54: 2852-2855, 1994

30. Duan DR, Pause A, Burgess WH, Aso T, Chen DY, Garrett KP, et al: Inhibition of transcription elongation by the VHL tumor suppressor protein. Science 269: 1402-1406, 1995.

31. Pause A, Lee S, Worrell RA, Chen DY, Burgess WH, Linehan WM, et al: The von Hippel-Lindau tumor-suppressor gene product forms a stable complex with human CUL-2, a member of the Cdc53 family of proteins. Proc Natl Acad Sci USA 94: 2156-2161, 1997.

32. Kibel A, Iliopoulos O, DeCaprio JA and Kaelin WG Jr: Binding of the von Hippel-Lindau tumor suppressor protein to Elongin B and C. Science 269: 1444-1446, 1995.

33. Berra E, Benizri E, Ginouvès A, Volmat V, Roux D and Pouyssèqur J: HIF prolyl-hydroxylase 2 is the key oxygen sensor setting low steady-state levels of HIF-1alpha in normoxia. EMBO J 22: 4082-4090, 2003.

34. Marsex JH, Stengel P, Doege K, Heikkinen P, Jokilehto T, Wagner T, et al: Hypoxia-inducible factor-1 (HIF-1) promotes its degradation by induction of HIF-alpha-proryl-4-hydroxylase. Biochem J 381: 761-767, 2004.

35. Pistollato F, Ramoazzo E, Abbadi S, Della Puppa A, Scienza R, D'Avella D, et al: Molecular mechanisms of HIF-1alpha modulation induced by oxygen tension and BMP2 in glioblastoma derived cells. PLoS One 4: e6206, 2009.

36. Barth S, Edlich F, Berchner-Pfannschmidt U, Gneuss S, Jahreis G, Hasgall PA, et al: Hypoxia-inducible factor prolyl-4-hydroxylase PHD2 protein abundance depends on integral membrane anchoring of FKBP38. J Biol Chem 284: 23046-23058, 2009.

37. Barth S, Nesper J, Hasgall PA, Wirthner R, Nytko KJ, Edlich F, et al: The peptidyl prolyl cis/trans isomerase FKBP38 determines hypoxia-inducible transcription factor prolyl-4-hydroxylase PHD2 protein stability. Mol Cell Biol 27: 3758-3768, 2007.

38. Luo W, Zhong J, Chang R, Hu H, Pandy A and Semenza GL: Hsp70 and CHIP selectively mediate ubiquition and degradation of hypoxia-inducible factor (HIF)-1alpha but Not HIF-2alpha. J Biol Chem 285: 3651-3663, 2010.

39. Isaacs JS, Jung YJ, Mimnaugh EG, Martinez A, Cuttitta F and Neckers LM: Hsp90 regulates a von Hippel Lindau-independent hypoxia-inducible factor-1 alpha-degradation pathway. J Biol Chem 277: 29936-29944, 2002.

40. Embi N, Rylatt DB and Cohen P: Glycogen synthase kinase-3 from rabbit skeletal muscle. Separation from cyclic-AMP-dependent protein kinase and phosphorylase kinase. Eur J Biochem 107: 519-527, 1980.

41. Luo J: Glycogen synthase kinase 3beta (GSK3beta) in tumorigenesis and cancer chemotherapy. Cancer Lett 273: 194-200, 2009.

42. Newqard CB, Brady MJ, O'Doherty RM and Saltiel AR: Organizing glucose disposal: emerging roles of glycogen targeting subunits of protein phosphatase-1. Diabetes 49: 1967-1977, 2000.

43. Samuels Y, Wang Z, Bardelli A, Silliman N, Ptak J, Szabo S, et al: High frequency of mutations of the PIK3CA gene in human cancers. Science 304: 554, 2004.

44. Shaw RJ and Cantley LC: Ras, PI(3)K and mTOR signaling controls tumour cell growth. Nature 441: 424-430, 2006.

45. Kuo KT, Mao TL, Jones S, Veras E, Ayhan A, Wang TL, et al: Frequent activating mutations of PIK3CA in ovarian clear cell carcinoma. Am J Pathol 174: 1597-1601, 2009.
46. Jones S, Wang TL, Shih leM, Mao TL, Nakayama K, Roden R, et al: Frequent mutations of chromatin remodeling gene ARID1A in ovarian clear cell carcinoma. Science 330: 228-231, 2010.

47. Kang S, Bader AG and Vogt PK: Phosphatidylinositol 3-kinase mutations identified in human cancer are oncogenic. Proc Natl Acad Sci USA 102: 802-807, 2005

48. Jiang BH, Jiang G, Zheng JZ, Lu Z, Hunter T and Vogt PK: Phosphatidyinositol 3-kinase signaling controls levels of hypoxiainducible factor 1. Cell Growth Differ 12: 363-369, 2001.

49. Martinive P, Defresne F, Quaghebeur E, Daneau G, Crokart N, Grégoire V, et al: Impact of cyclen hypoxia on HIF-1alpha regulation in endothelial cell - new insights for anti-tumor treatments. FEBS J 276: 509-518, 2009.

50. Mottet D, Dumont V, Deccache Y, Demazy C, Ninane N, Rase M, et al: Regulation of hypoxia-inducible factor-lalpha protein level during hypoxic conditions by the phosphatidylinositol 3-kinase/ Akt/glycogen synthase kinase 3beta pathway in HepG2 cells. J Biol Chem 278: 31277-31285, 2003.

51. An WG, Kanekal M, Simon MC, Maltepe E, Blagosklonny MV and Neckers LM: Stabilization of wild-type p53 by hypoxia-inducible factor 1alpha. Nature 392: 405-408, 1998.

52. Zhou BP, Deng J, Xia W, Xu J, Li YM, Gunduz M and Hung MC: Dual regulation of Snail by GSK-3beta-mediated phosphorylation in control of epithelial-mesenchymal transition. Nat Cell Biol 6: 931-940, 2004

53. Pruksakom D, Lirdprapamonqkol K, Chokchaichamnankit D, Subhasitanont P, Chiablaem K, Svasti J, et al: Metabolic alteration of HepG2 in scaffold-based 3-D culture: proteomic approach. Proteomics 10: 3896-3904, 2010.

54. Fischbach C, Chen R, Matsumoto T, Schmelzle T, Brugge JS, Polverini PJ, et al: Engineering tumors with 3D scaffolds. Nat Methods 4: 855-860, 2007.

55. Friedrich J, Seidel C, Ebner R and Kunz-Schuqhart LA: Spheroidbased drug screen: considerations and practical approach. Nat Protoc 4: 309-324, 2009.

56. Matsushima H, Shibata S, Asakura T, Matsuura T, Maehashi $\mathrm{H}$, Ishii Y, Eda H, Aoki K, Iida Y, Morikawa T and Ohkawa K: Three-dimensional culture promotes reconstitution of the tumorspecific hypoxic microenvironment under TGF $\beta$ stimulation. Int J Oncol 39: 1327-1336, 2011.

57. Comeford KM, Wallace TJ, Karhausen J, Louis NA, Montalto MC and Colqan SP: Hypoxia-inducible factor-1-dependent regulation of the multidrug resistance (MDR1) gene. Cancer Res 62: 3387-3394, 2002.

58. Gottesman MM, Fojo T and Bates SE: Multidrug resistance in cancer: role of ATP-dependent transporters. Nat Rev Cancer 2: 48-58, 2002.

59. Hurley LH: DNA and its associated processes as targets for cancer therapy. Nat Rev Cancer 2: 188-200, 2002.

60. Lee K, Qisn DZ, Rey S, Wei H, Liu JO and Semnza GL: Anthracycline chemotherapy inhibits HIF-1 transcriptional activity and tumor-induced mobilization of circulating angiogenic cells. Proc Natl Acad Sci USA 406: 2353-2358, 2009.

61. Yamazaki Y, Hasebe Y, Egawa K, Nose K, Kunimoto S and Ikeda D: Anthracyclines, small-molecule inhibitors of hypoxiainducible factor-1 alpha activation. Biol Pharm Bull 29: 1999-2003, 2006.

62. Tsuruo T, Kawabata H, Nagumo N, Iida H, Kitatani Y, Tsukagoshi S and Sakurai Y: Potentiation of antitumor agents by calcium channel blockers with special reference to cross-resistance patterns. Cancer Chemother Pharmacol 15: 16-19, 1985.

63. Dong J, Naito M, Tatsutaa T, Seimiya H, Johdo O and Tsuruo T: Difference between the resistance mechanism of aclacinomycinand adriamycin-resistant P388 cell lines. Oncol Res 7: 245-252, 1995.

64. Tsuruo T, Iida-Saito H, Kawabata H, Oh-hara T, Hamada H and Utakoji T: Characteristics of resistance to adriamycin in human myelogenous leukemia K562 resistant to adriamycin and in isolated clones. Jpn J Cancer Res 77: 682-692, 1986. 